\title{
Risk Factors for Low Back Pain and Spine Surgery
}

\section{A Retrospective Cohort Study in Soldiers}

Joseph R. Kardouni, PhD, PT, ${ }^{1}$ Tracie L. Shing, MPH, ${ }^{1}$ Daniel I. Rhon, DSc, $\mathrm{PT}^{2,3}$

From the ${ }^{1}$ U.S. Army Research Institute of Environmental Medicine, Natick, Massachusetts;

${ }^{2}$ Center for the Intrepid, Brooke Army Medical Center, Joint Base San Antonio, Texas; and

${ }^{3}$ Doctoral Program in Physical Therapy, U.S. Army-Baylor University, San Antonio, Texas

Address correspondence to: Joseph R. Kardouni, PhD, PT, U.S. Army Research Institute of

Environmental Medicine, Military Performance Division, 10 General Greene Avenue, Building

42, Natick MA 01760. E-mail: joseph.r.kardouni.mil@mail.mil. 
Introduction: Musculoskeletal low back pain (LBP) is commonly treated symptomatically, with practice guidelines advocating reserving surgery for cases that fail conservative care. This study examined medical comorbidities and demographic variables as risk factors for chronic/recurrent LBP, spinal surgery, and time to surgery.

Methods: A 2015 retrospective cohort study was conducted in U.S. Army soldiers ( $N=1,092,420)$ from 2002 to 2011. Soldiers with medical encounters for LBP were identified using ICD-9 codes. Surgical treatment for LBP was identified according to Current Procedural Terminology codes. Comorbid medical conditions (psychological disorders, sleep disorders, tobacco use, alcohol use, obesity) and demographic variables were examined as risk factors for chronic/recurrent LBP within 1 year of the incident encounter, surgery for LBP, and time to surgery.

Results: Of 383,586 patients with incident LBP, 104,169 (27\%) were treated for chronic/recurrent LBP and 7,446 (1.9\%) had surgery. Comorbid variables showed increased risk of chronic/recurrent LBP ranging from $26 \%$ to $52 \%$. Tobacco use increased risk for surgery by $33 \%$ (risk ratio, $1.33 ; 95 \% \mathrm{CI}=1.24,1.44$ ). Comorbid variables showed $10 \%-42 \%$ shorter time to surgery (psychological disorders, time ratio $[\mathrm{TR}]=0.90,95 \% \mathrm{CI}=0.83,0.98$; sleep disorders, $\mathrm{TR}=0.68,95 \% \mathrm{CI}=0.60,0.78$; obesity, $\mathrm{TR}=0.88,95 \% \mathrm{CI}=0.79,0.98$; tobacco use, $\mathrm{TR}=0.58$, 95\% CI=0.54, 0.63; alcohol use, $\mathrm{TR}=0.85,95 \% \mathrm{CI}=0.70,1.05)$. Women showed $20 \%$ increased risk of chronic/recurrent LBP than men but $42 \%$ less risk of surgery.

Conclusions: In the presence of comorbidities associated with mental health, sleep, obesity, tobacco use, and alcohol use, LBP shows increased risk of becoming chronic/recurrent and faster time to surgery. 


\section{Introduction}

Low back pain (LBP) is one of the most commonly treated musculoskeletal conditions and is a leading cause of physical disability. ${ }^{1}$ A recent systematic review and meta-analysis ${ }^{2}$ on the incidence and risk factors for first-time LBP calculated an incidence proportion (percentage of the study sample who developed LBP) in community settings over 12-24 months as $26 \%$ (95\% $\mathrm{CI}=24 \%, 28 \%$ ), based on data from three study samples in the $1990 \mathrm{~s}^{3-5}$ The same meta-analysis also found that three occupational cohorts with back pain $^{6-8}$ had a combined incidence proportion of $26 \%(95 \% \mathrm{CI}=6 \%, 46 \%)$, but there was a great deal of variability due to subject heterogeneity. In Department of Defense personnel, cases of LBP as a function of time in military service have incidence rates ranging from 32.9 to 57.0 per 1,000 person years. ${ }^{9-12}$ As Department of Defense personnel are recruited from the general U.S. population and participation in sports and physical training is a leading source for musculoskeletal injuries within the Army, ${ }^{13}$ the rate of LBP in the military may be representative of physically active adults in the general population. ${ }^{14,15}$

Comorbid medical conditions may play a part in developing LBP or in LBP progressing to a chronic or recurrent condition. Tobacco use,${ }^{16,17}$ alcohol use, ${ }^{18,19}$ obesity, ${ }^{20}$ sleep disturbances, ${ }^{21-}$ ${ }^{23}$ and mental health disorders ${ }^{2,24-26}$ have been identified as risk factors for LBP. Furthermore, people with LBP and medical comorbidities of nicotine dependence, ${ }^{27}$ psychological disorders, ${ }^{24,26-28}$ sleep disturbance, ${ }^{29}$ or alcohol use ${ }^{18}$ have shown increased risk for LBP becoming chronic or debilitating. These comorbid medical conditions are usually examined in isolation among subsets of the population as factors associated with LBP; therefore, a multifactorial investigation in a large cohort is lacking. These results would provide healthcare 
practitioners with more information about comprehensive health approaches to potentially prevent or manage LBP, rather than a traditional focus that often relies on symptoms or findings from imaging studies.

There are several national and international guidelines available for the treatment of $\mathrm{LBP},{ }^{30}$ with surgical referral for non-emergent cases of LBP often recommended after failure of comprehensive conservative treatment. ${ }^{30-32}$ Although factors such as patient age, duration of conservative management of symptoms, patient weight, smoking history, and psychological factors are considered when considering surgery for LBP, ${ }^{31}$ direct evidence is lacking as to whether these factors may increase risk for surgery or hasten time to surgery for patients with LBP.

The purpose of this study was to examine demographic and medical risk factors associated with developing incident and chronic LBP and the risk of requiring surgical treatment. This study was designed to quantify the rate of chronic or recurrent LBP that developed within 1 year of an initial medical encounter for LBP. Time from initial diagnosis until surgical intervention was also examined.

\section{Methods}

This retrospective cohort study was conducted in 2015 using data from the Total Army Injury and Health Outcomes Database. The database includes medical encounter data and personnel data on all active duty U.S. Army soldiers and exists for the purpose of conducting 
epidemiologic research within the Army. This study was approved by the IRB of the U.S. Army Research Institute of Environmental Medicine.

\section{Sample Population}

The ICD-9 codes associated with LBP (Appendix Table 1) conditions were used to identify incident cases (first medical encounter) of LBP among active duty soldiers from 2002 to 2011. To ensure capture of incident cases of musculoskeletal LBP while in the military, medical encounter data were screened to exclude soldiers with a history of LBP any time prior to the study period or potential non-musculoskeletal LBP. ${ }^{33}$ Records for $1,092,420$ active duty soldiers from 2002 to 2011 were screened for LBP, identifying 383,586 soldiers with an incident case of LBP during 2002-2011.

Chronic or recurrent cases of LBP were defined as any subsequent LBP-related diagnosis code in medical encounter data $>3$ months ${ }^{26}$ and $\leq 1$ year following initial diagnosis. People who underwent spinal surgery within the first 3 months following the initial LBP medical encounter $(n=195)$ were not included as a chronic or recurrent case patient. Soldiers were followed from incident medical encounter for LBP until the end of the 1-year follow-up period or until they left the service if they were discharged $<1$ year from the incident LBP medical encounter. Potential risk factors for LBP included both demographic factors (age, sex, race, education level, marital status) and comorbid medical conditions (psychological disorders, sleep disorders, obesity, tobacco use, and alcohol use). Age was subdivided into four categories ( $<20$ years, 20-29 years, 30-39 years, and $\geq 40$ years). Race was categorized according to self-reported race contained in Army personnel data (white, black, Asian, American Indian, and other). Education was divided into four categories (did not finish high school, high school graduate, college education, and 
advanced degree). Marital status was categorized as single, married, and other (divorced, widowed, or separated). Comorbid medical conditions were identified by ICD-9 codes (Appendix Table 2) present within medical encounter data prior to initial LBP diagnosis or $\leq 1$ year following LBP diagnosis.

Patients with LBP who had spinal surgery were identified using Current Procedural Terminology codes indicative of spinal surgery (Appendix Table 3 ) ${ }^{33}$ Survival time to surgery was calculated as the number of days from the first LBP encounter until the spinal surgery encounter. For soldiers who did not undergo surgery, follow-up time was calculated as the time from the incident LBP encounter to the last LBP-related encounter in the record.

\section{Statistical Analysis}

A 10-year incidence rate was calculated and reported per 1,000 person years, and the rate of chronic or recurrent cases was also calculated. Poisson regression was used to calculate incidence rate ratios for risk factors associated with LBP using the demographic factors and the comorbid medical conditions. Log binomial regression methods were used to calculate risk ratios (RRs) with 95\% CIs for risk factors of chronic or recurrent LBP and risk factors of spinal surgery. Models were fit using each of the comorbid variables and the number of comorbidities as the primary risk factor and adjusting for demographic covariates. Non-parametric KaplanMeier survival curves were evaluated for all risk factors of spinal surgery and assessed using the log-rank test. Right censoring was used to account for differences in follow-up time and survival time due to soldiers leaving the service or reaching the end of the study period. Owing to nonproportionality of hazards, adjusted survival analyses were performed using an accelerated failure time model best fit with a gamma distribution. Time ratios (TRs) were calculated for 
survival time until surgery. All statistical tests were performed using SAS, version 9.3, with the level of significance set at $\alpha=0.05$.

\section{Results}

During 2002-2011, there were 383,586 incident cases of LBP among active duty soldiers (Table 1). This resulted in an incidence rate of 118.2 per 1,000 person years (incident proportion, $35.1 \%)$. Of the incident case patients, $1.9 \%(n=7,446)$ went on to have spinal surgery. The median follow-up time among those who went on to have surgery was 647 days (interquartile range, 1,121 days), whereas the median follow-up time among those with LBP who did not have surgery was 65 days [interquartile range, 758 days]. Of the incident case patients, $27.2 \%$ $(n=104,169)$ developed chronic or recurrent symptoms within 1 year.

The demographic breakdown of the study population and results from the Poisson regression are available in Table 1. Women showed an $88 \%$ greater likelihood of having a medical visit for LBP than men (incidence rate ratio, $1.88 ; 95 \% \mathrm{CI}=1.85,1.92$ ). Both younger and older age groups showed increased incidence of LBP compared with the ref group aged 20-29 years. Not graduating high school was associated with increased risk for LBP, whereas an advanced degree was associated with a lower risk for LBP. Soldiers who were married or divorced/widowed/separated had higher incidences of LBP than single soldiers. Slight differences were also seen for race as a risk factor for LBP (Table 1).

When examining factors related to chronic or recurrent LBP (Table 2), the same trends as incident LBP were noted for sex (women, $20 \%$ greater risk), level of education, and marital 
status. Developing chronic or recurrent LBP appeared to increase with age, with the youngest group of soldiers (aged <20 years) showing less risk of developing chronic or recurrent LBP $(\mathrm{RR}=0.93,95 \% \mathrm{CI}=0.91,0.94)$ and those aged $\geq 30$ years being more likely to develop chronic or recurrent LBP compared with those aged 20-29 years. In contrast to the findings for incident LBP related to race, black race was related to slightly decreased risk of developing chronic or recurrent LBP compared with the ref group of white soldiers $(\mathrm{RR}=0.98,95 \% \mathrm{CI}=0.96,0.99)$.

Associations between comorbidities and incident LBP or chronic/recurrent LBP are shown in Table 3. Soldiers seeking medical care for psychological disorders, sleep disorders, obesity, tobacco use, or alcohol use were less likely to be seen for incident LBP than soldiers without medical encounters for each respective disorder. However, the risk for LBP becoming chronic or recurrent increased in the presence of each of these comorbidities. Interestingly, risk of developing chronic or recurrent LBP increased incrementally when multiple comorbidities were present, with point RR estimates ranging from 1.31 to 2.24 . Because the $95 \%$ CIs surrounding the point estimates did not overlap, the risk for chronicity or recurrence increased distinctly with a higher number of comorbidities present.

According to Kaplan-Meier Survival curves and log-rank tests, there were significant differences in survival for sex, age categories, education, marital status, race, and comorbidity categories $(p<0.0001)$. Appendix Figure 1 represents the time to surgery for LBP patients with each of the comorbidities and for those with more than one of the comorbidities. The results of the accelerated failure time model and adjusted survival TRs are shown in Table 4. Although women were more likely to be seen for incident and chronic/recurrent LBP, they showed lower risk for 
surgery $(\mathrm{RR}=0.58,95 \% \mathrm{CI}=0.54,0.63)$ and had a $97 \%$ longer time to surgery compared with men $(\mathrm{TR}=1.97,95 \% \mathrm{CI}=1.84,2.12)$. Compared with soldiers aged 20-29 years, those aged $<20$ years were less likely to have surgery and had a longer time to surgery, whereas soldiers aged $\geq 30$ years were more likely to have surgery and had a significantly shorter times to surgery. Compared with soldiers with a high school education, soldiers with less than a high school education showed no difference in risk of surgery, but had a shorter time to surgery, whereas soldiers with an advanced degree were less likely to have surgery and had a longer time to surgery. Both married soldiers and soldiers who were divorced, separated, or widowed were more likely to have surgery and had shorter times to surgery than single soldiers. White soldiers seemed to be most at risk of surgery and had the shortest time to surgery.

Soldiers with multiple comorbidities $(\mathrm{RR}=1.27,95 \% \mathrm{CI}=1.20,1.34)$ or documented tobacco use $(\mathrm{RR}=1.33,95 \% \mathrm{CI}=1.24,1.44)$ had significantly increased risk for surgery compared with soldiers with no comorbid diagnoses (Table 4). Additionally, soldiers with comorbid diagnoses had significantly shorter times to surgery than soldiers with no other comorbid condition. After adjusting for demographic covariates, soldiers with multiple comorbidities had a 51\% shorter time to surgery than soldiers with no comorbid diagnosis ( $\mathrm{TR}=0.49,95 \% \mathrm{CI}=0.46,0.52)$. All of the comorbidities except for alcohol use showed shorter time to surgery ranging from $10 \%$ to $42 \%$ sooner surgical intervention (Table 4 ), with tobacco use ( $42 \%$ sooner, $\mathrm{TR}=0.58,95 \%$ $\mathrm{CI}=0.54,0.63)$ and sleep disorders $(32 \%$ sooner, $\mathrm{TR}=0.68,95 \% \mathrm{CI}=0.60,0.78)$ showing the greatest effect.

\section{Discussion}


This study showed that individuals receiving medical care for LBP in the presence of psychological disorders, sleep disturbances, obesity, tobacco use, and alcohol abuse were more likely to require care for chronic or recurrent LBP than those without these comorbidities. Additionally, the risk of chronicity or recurrence increased stepwise with the increasing number of comorbidities. The presence of two comorbidities increased the risk for chronicity or recurrence greater than any comorbidity in isolation, and as additional comorbidities were present, the risk of chronicity or recurrence continued to increase, with no overlap in the CIs. The relationship between these comorbidities and LBP is consistent with prior work suggesting psychological disorders, ${ }^{2,24-26,34}$ disturbances of sleep, ${ }^{21-23}$ obesity, ${ }^{17}$ tobacco use, ${ }^{16,20}$ and alcohol use $^{18,19}$ are associated with LBP. However, these factors were usually examined separately, and two recent reviews ${ }^{2,34}$ noted that heterogeneity among studies of LBP made pooling data and study results difficult. The current study examined all of these comorbid medical conditions simultaneously within a population of active adults and examined relationships with chronic/recurrent LBP and surgical treatment for LBP.

This study is novel with respect to developing statistical models for the risk of surgical intervention, and is the first to examine the time from initial care until spine surgery in a population with LBP. This study showed that a history of tobacco use increased the risk of spine surgery by $33 \%$. Tobacco use also resulted in surgical intervention $42 \%$ faster than in someone without the comorbidities examined within this study. Patients with two or more of the comorbidities examined within this study showed a $27 \%$ increased risk of surgery, with a $51 \%$ faster time to surgery. Taken individually, all of the comorbidities except for alcohol use were associated with faster time to spine surgery. These findings merit further consideration, because 
a precursor to surgical intervention is often a failure of conservative treatment. ${ }^{30-32}$ In this cohort, psychological disorders, history of tobacco use, sleep disorders, and obesity were not only associated with an increased risk of developing chronic LBP but may have also been related to quicker failure of conservative treatment than in patients without these comorbidities. Previous publications have reported variations in clinical indications for spinal surgery based on surgeons' training and geographic trends. ${ }^{31,35,36}$ The military healthcare system, however, includes a heterogeneous mix of providers and geographic locales, likely minimizing the effects of surgeons' training and geographic trends within this cohort. The findings of the current study identified patient-specific factors that broadly influenced surgical intervention beyond surgeons' professional background and geographic location.

The incidence rate for LBP in the current cohort was higher than previous reports of LBP in military personnel, ${ }^{11,12}$ primarily due to the more inclusive list of LBP related medical diagnoses. In turn, this may provide a more accurate representation of LBP in U.S. Army soldiers. As sports- and exercise-related injuries are a leading source of the musculoskeletal injuries within the Army,${ }^{13}$ these results may also have generalizability to other populations of active adults. ${ }^{15}$ The findings of this study with respect to sex are consistent with previous reports that women seek medical care for LBP at higher rates than men. ${ }^{11,12,37-39}$ However, because the current study showed higher surgical rates in men, overall healthcare cost for men could be higher than that for women. The general trend in this study was that increasing age was associated with increased risk for both incident and chronic or recurrent back pain, as well as increased risk for surgery. This is in line with other reports that higher rates of LBP are typically seen with older age, particularly into the 40s and beyond. ${ }^{11,39}$ The exception to this trend was with individuals aged 
$<20$ years, as they showed higher risk of incident LBP than those aged 20-29 years. Similar to prior research that has linked lower education levels with increased rates and duration of $\mathrm{LBP},{ }^{34,40}$ individuals with less formal education in this cohort were more likely to have a medical encounter for incident LBP. Though education may sometimes be considered a proxy for SES, in this study, it is likely a reflection of work duties and personal interests. Marital status has shown a relationship with LBP, with individuals identified as single showing lower risk for LBP. ${ }^{12,41}$ The same trend was noted in the current study, where single individuals showed lower rates of LBP, less risk for developing chronic or recurrent LBP, and longer times to surgery than married or formerly married individuals.

The primary strength of this investigation is the use of a population-level cohort. The closed healthcare system used by the military eliminates recruitment bias by allowing for nearly complete capture of all medical encounters for all service members, regardless of whether they were seen at military or civilian facilities. All soldiers also have equal access to care (regardless of rank), which eliminates potential confounding due to socioeconomic factors. The authors were also able to identify true service-related incident cases by excluding individuals with medical encounters for LBP that occurred prior to the beginning of the study.

\section{Limitations}

There were also several limitations associated with this study. The data were extracted from medical encounters and not an examination of individuals' medical records. Therefore, many text-based fields such as factors associated with mechanism of injury or onset of symptoms were not available. Additionally, findings from the clinical examination were not available, so factors associated with symptom severity and function were not examined within this study. With 
respect to the comorbid conditions examined in this study, information was limited only to people with conditions significant enough to seek medical care. Therefore, it is likely that there are individuals with the comorbid conditions who were not identified in this study owing to the subclinical nature of their psychological, sleep, body weight, tobacco, or alcohol disorder. This would tend to bias the results toward conservative estimates of the effects of these comorbid variables. Future studies should examine longer durations past 1 year (2-5 years) to see if these trends continue for longer periods of time.

\section{Conclusions}

Patients with LBP in the presence of treatable comorbidities thought to affect prognosis (psychological disorders, sleep disorders, obesity, tobacco use, or alcohol use) were more likely to develop chronic or recurrent LBP, and the risk for chronic or recurrent LBP increased as the number of comorbidities increased. Tobacco use increased the risk of surgery for LBP, as did presence of multiple comorbidities. Women were more likely to be treated for LBP and showed greater risk for developing chronic LBP, but showed lower risk for surgery. Increased risk of developing chronic LBP and having surgical treatment for LBP were seen in patients aged $\geq 30$ years. Therefore, both modifiable and non-modifiable factors affect risk for chronic LBP and surgical intervention in active adults with LBP and should be considered during treatment. 


\section{Acknowledgments}

The opinions or assertions contained herein are the private views of the author(s) and are not to be construed as official or reflecting the views of the Department of the Army or the Department of Defense. Any citations of commercial organizations and trade names in this report do not constitute an official Department of the Army endorsement or approval of the products or services of these organizations.

The investigators have adhered to the policies for protection of human subjects as prescribed in Department of Defense Instruction 3216.02 and the research was conducted in adherence with the provisions of 32 CFR Part 219.

Author contributions: study concept and design: Kardouni, Shing, Rhon; acquisition, analyses, or interpretation of data: Kardouni, Shing; drafting of the manuscript: Kardouni, Shing, Rhon; critical revision of the manuscript for important intellectual content: Kardouni, Shing, Rhon; approval of final version of the manuscript: Kardouni, Shing, Rhon.

No financial disclosures were reported by the authors of this paper. 


\section{References}

1. Murray CJ, Atkinson C, Bhalla K, et al. The state of U.S. health, 1990-2010: burden of diseases, injuries, and risk factors. JAMA. 2013;310(6):591-608. http://dx.doi.org/10.1001/jama.2013.13805.

2. Taylor JB, Goode AP, George SZ, Cook CE. Incidence and risk factors for first-time incident low back pain: a systematic review and meta-analysis. Spine J. 2014;14(10):2299-2319. http://dx.doi.org/10.1016/j.spinee.2014.01.026.

3. Croft PR, Papageorgiou AC, Ferry S, Thomas E, Jayson MI, Silman AJ. Psychologic distress and low back pain. Evidence from a prospective study in the general population. Spine (Phila Pa 1976). 1995;20(24):2731-2737. http://dx.doi.org/10.1097/00007632$\underline{199512150-00015 .}$

4. Macfarlane GJ, Thomas E, Papageorgiou AC, Croft PR, Jayson MI, Silman AJ. Employment and physical work activities as predictors of future low back pain. Spine (Phila Pa 1976). 1997;22(10):1143-1149. http://dx.doi.org/10.1097/00007632199705150-00015.

5. Symmons DP, van Hemert AM, Vandenbroucke JP, Valkenburg HA. A longitudinal study of back pain and radiological changes in the lumbar spines of middle aged women. II. Radiographic findings. Ann Rheum Dis. 1991;50(3):162-166. http://dx.doi.org/10.1136/ard.50.3.162.

6. George SZ, Childs JD, Teyhen DS, et al. Predictors of occurrence and severity of first time low back pain episodes: findings from a military inception cohort. PLoS One. 2012;7(2):e30597. http://dx.doi.org/10.1371/journal.pone.0030597. 
7. Masset DF, Piette AG, Malchaire JB. Relation between functional characteristics of the trunk and the occurrence of low back pain. Associated risk factors. Spine (Phila Pa 1976). 1998;23(3):359-365. http://dx.doi.org/10.1097/00007632-199802010-00015.

8. Pietri F, Leclerc A, Boitel L, Chastang JF, Morcet JF, Blondet M. Low-back pain in commercial travelers. Scand J Work Environ Health. 1992;18(1):52-58. http://dx.doi.org/10.5271/sjweh.1614.

9. Knox JB, Orchowski JR, Scher DL, Owens BD, Burks R, Belmont PJ, Jr. Occupational driving as a risk factor for low back pain in active-duty military service members. Spine J. 2014;14(4):592-597. http://dx.doi.org/10.1016/j.spinee.2013.06.029.

10. Ernat J, Knox J, Orchowski J, Owens B. Incidence and risk factors for acute low back pain in active duty infantry. Mil Med. 2012;177(11):1348-1351. http://dx.doi.org/10.7205/MILMED-D-12-00183.

11. Knox JB, Orchowski JR, Owens B. Racial differences in the incidence of acute low back pain in United States military service members. Spine (Phila Pa 1976). 2012;37(19):1688-1692. http://dx.doi.org/10.1097/BRS.0b013e318255a07b.

12. Knox J, Orchowski J, Scher DL, Owens BD, Burks R, Belmont PJ. The incidence of low back pain in active duty United States military service members. Spine (Phila Pa 1976). 2011;36(18):1492-1500. http://dx.doi.org/10.1097/BRS.0b013e3181f40ddd.

13. Lauder TD, Baker SP, Smith GS, Lincoln AE. Sports and physical training injury hospitalizations in the army. Am J Prev Med. 2000;18(3 Suppl):118-128. http://dx.doi.org/10.1016/S0749-3797(99)00174-9. 
14. Scofield DE, Kardouni JR. The Tactical Athlete: A Product of 21st Century Strength and Conditioning. Strength Cond J. 2015;37(4):2-7.

http://dx.doi.org/10.1519/SSC.0000000000000149.

15. Rothman KJ, Greenland S, Lash TL. Modern epidemiology. 3rd ed. Philadelphia: Wolters Kluwer Health/Lippincott Williams \& Wilkins; 2008.

16. Behrend C, Prasarn M, Coyne E, Horodyski M, Wright J, Rechtine GR. Smoking Cessation Related to Improved Patient-Reported Pain Scores Following Spinal Care. J Bone Joint Surg Am. 2012;94(23):2161-2166. http://dx.doi.org/10.2106/JBJS.K.01598.

17. Shiri R, Karppinen J, Leino-Arjas P, Solovieva S, Viikari-Juntura E. The association between smoking and low back pain: a meta-analysis. Am J Med. 2010;123(1):87. http://dx.doi.org/10.1016/j.amjmed.2009.05.028.

18. Ferreira PH, Pinheiro MB, Machado GC, Ferreira ML. Is alcohol intake associated with low back pain? A systematic review of observational studies. Man Ther. 2013;18(3):183190. http://dx.doi.org/10.1016/j.math.2012.10.007.

19. Gorman DM, Potamianos G, Williams KA, Frank AO, Duffy SW, Peters TJ. Relationship between alcohol abuse and low back pain. Alcohol Alcohol. 1987;22(1):6163.

20. Shiri R, Karppinen J, Leino-Arjas P, Solovieva S, Viikari-Juntura E. The association between obesity and low back pain: a meta-analysis. Am J Epidemiol. 2010;171(2):135154. http://dx.doi.org/10.1093/aje/kwp356.

21. Auvinen JP, Tammelin TH, Taimela SP, et al. Is insufficient quantity and quality of sleep a risk factor for neck, shoulder and low back pain? A longitudinal study among 
adolescents. Eur Spine J. 2010;19(4):641-649. http://dx.doi.org/10.1007/s00586-009$\underline{1215-2 .}$

22. Alsaadi SM, McAuley JH, Hush JM, et al. Poor sleep quality is strongly associated with subsequent pain intensity in patients with acute low back pain. Arthritis Rheumatol. 2014;66(5):1388-1394. http://dx.doi.org/10.1002/art.38329.

23. Alsaadi SM, McAuley JH, Hush JM, Maher CG. Prevalence of sleep disturbance in patients with low back pain. Eur Spine J. 2011;20(5):737-743. http://dx.doi.org/10.1007/s00586-010-1661-x.

24. Linton SJ. A review of psychological risk factors in back and neck pain. Spine (Phila Pa 1976). 2000;25(9):1148-1156. http://dx.doi.org/10.1097/00007632-200005010-00017.

25. Angstman KB, Bansal S, Chappell DH, Bock FA, Rasmussen NH. Effects of concurrent low back conditions on depression outcomes. J Am Osteopath Assoc. 2013;113(7):530537. http://dx.doi.org/10.7556/jaoa.2013.004.

26. Andersson GB. Epidemiological features of chronic low-back pain. Lancet. 1999;354(9178):581-585. http://dx.doi.org/10.1016/S0140-6736(99)01312-4.

27. Shaw WS, Means-Christensen AJ, Slater MA, et al. Psychiatric disorders and risk of transition to chronicity in men with first onset low back pain. Pain Med. 2010;11(9):1391-1400. http://dx.doi.org/10.1111/j.1526-4637.2010.00934.x.

28. Ellegaard H, Pedersen BD. Stress is dominant in patients with depression and chronic low back pain. A qualitative study of psychotherapeutic interventions for patients with non-specific low back pain of 3-12 months' duration. BMC Musculoskelet Disord. 2012;13:166. http://dx.doi.org/10.1186/1471-2474-13-166. 
29. Eadie J, van de Water AT, Lonsdale C, et al. Physiotherapy for sleep disturbance in people with chronic low back pain: results of a feasibility randomized controlled trial. Arch Phys Med Rehabil. 2013;94(11):2083-2092. http://dx.doi.org/10.1016/j.apmr.2013.04.017.

30. Koes BW, van Tulder M, Lin CW, Macedo LG, McAuley J, Maher C. An updated overview of clinical guidelines for the management of non-specific low back pain in primary care. Eur Spine J. 2010;19(12):2075-2094. http://dx.doi.org/10.1007/s00586$\underline{010-1502-y}$.

31. Willems P. Decision making in surgical treatment of chronic low back pain: the performance of prognostic tests to select patients for lumbar spinal fusion. Acta Orthop Suppl. 2013;84(349):1-35. http://dx.doi.org/10.3109/17453674.2012.753565.

32. Savigny $\mathrm{P}$, Watson $\mathrm{P}$, Underwood M. Early management of persistent non-specific low back pain: summary of NICE guidance. BMJ. 2009;338:b1805. http://dx.doi.org/10.1136/bmj.b1805.

33. Fritz JM, Childs JD, Wainner RS, Flynn TW. Primary care referral of patients with low back pain to physical therapy: impact on future health care utilization and costs. Spine (Phila Pa 1976). 2012;37(25):2114-2121.

http://dx.doi.org/10.1097/BRS.0b013e31825d32f5.

34. Hoy D, Brooks P, Blyth F, Buchbinder R. The Epidemiology of low back pain. Best Pract Res Clin Rheumatol. 2010;24(6):769-781. http://dx.doi.org/10.1016/j.berh.2010.10.002. 
35. Weinstein JN, Lurie JD, Olson PR, Bronner KK, Fisher ES. United States' trends and regional variations in lumbar spine surgery: 1992-2003. Spine (Phila Pa 1976). 2006;31(23):2707-2714. http://dx.doi.org/10.1097/01.brs.0000248132.15231.fe.

36. Irwin ZN, Hilibrand A, Gustavel M, et al. Variation in surgical decision making for degenerative spinal disorders. Part II: cervical spine. Spine (Phila Pa 1976). 2005;30(19):2214-2219. http://dx.doi.org/10.1097/01.brs.0000181056.76595.f7.

37. Freburger JK, Holmes GM, Agans RP, et al. The rising prevalence of chronic low back pain. Arch Intern Med. 2009;169(3):251-258. http://dx.doi.org/10.1001/archinternmed.2008.543.

38. Ferreira ML, Machado G, Latimer J, Maher C, Ferreira PH, Smeets RJ. Factors defining care-seeking in low back pain--a meta-analysis of population based surveys. Eur J Pain. 2010;14(7):747. http://dx.doi.org/10.1016/j.ejpain.2009.11.005.

39. Jordan KP, Kadam UT, Hayward R, Porcheret M, Young C, Croft P. Annual consultation prevalence of regional musculoskeletal problems in primary care: an observational study. BMC Musculoskelet Disord. 2010;11:144. http://dx.doi.org/10.1186/1471-2474-11-144.

40. Dionne CE, Von Korff M, Koepsell TD, Deyo RA, Barlow WE, Checkoway H. Formal education and back pain: a review. J Epidemiol Community Health. 2001;55(7):455-468. http://dx.doi.org/10.1136/jech.55.7.455.

41. Biglarian A, Seifi B, Bakhshi E, et al. Low back pain prevalence and associated factors in Iranian population: findings from the national health survey. Pain Res Treat. 2012;2012:653060. http://dx.doi.org/10.1155/2012/653060. 
Table 1. Demographics, Incidence Rates (IR) and Adjusted Incidence Rate Ratios (IRR) for Active Duty Soldiers 2002-2011

\begin{tabular}{|c|c|c|c|c|c|c|}
\hline \multirow{2}{*}{$\begin{array}{l}\text { Demographics } \\
\text { Population size }\end{array}$} & \multirow{2}{*}{$\begin{array}{c}\begin{array}{c}\text { Total } \\
\text { population }\end{array} \\
1,092,420\end{array}$} & \multicolumn{2}{|c|}{$\begin{array}{l}\text { Cases } \\
\mathrm{n}(\%)^{\mathrm{a}}\end{array}$} & \multirow{2}{*}{$\begin{array}{c}\begin{array}{c}\text { Person- } \\
\text { years }\end{array} \\
3,244,821.7\end{array}$} & \multirow{2}{*}{$\begin{array}{c}\text { Unadjusted } \\
\text { IR }\end{array}$} & \multirow[t]{2}{*}{$\begin{array}{c}\text { Adjusted IRR } \\
\text { [95\% CI] }\end{array}$} \\
\hline & & 383,586 & $(35.1)$ & & & \\
\hline \\
\hline Females & 167,621 & 75,592 & $(45.1)$ & $375,471.1$ & 201.33 & $1.88[1.85,1.92]$ \\
\hline Males & 924,732 & 307,992 & (33.3) & $2,869,286.3$ & 107.34 & ref \\
\hline Unknown & 67 & 2 & (3.0) & 64.3 & 31.10 & \\
\hline \multicolumn{7}{|l|}{ Age group } \\
\hline$<20$ & 354,342 & 111,343 & (31.4) & $944,248.3$ & 117.92 & $1.06[1.05,1.08]$ \\
\hline $20-29$ & 564,665 & 189,799 & (33.6) & $1,669,271.3$ & 113.70 & ref \\
\hline $30-39$ & 137,853 & 65,252 & $(47.3)$ & $524,057.4$ & 124.51 & $1.07[1.05,1.10]$ \\
\hline$\geq 40$ & 34,680 & 16,937 & $(48.8)$ & $105,007.9$ & 161.29 & $1.57[1.51,1.63]$ \\
\hline Unknown & 880 & 255 & (29.0) & $2,236.8$ & 114.00 & \\
\hline \multicolumn{7}{|l|}{ Education } \\
\hline $\begin{array}{l}\text { Did not finish high } \\
\text { school }\end{array}$ & 36,089 & 12,254 & $(34.0)$ & $89,829.1$ & 136.41 & $1.14[1.10,1.19]$ \\
\hline High school graduate & 749,117 & 265,392 & (35.4) & $2,238,903.8$ & 118.54 & ref \\
\hline College & 263,553 & 92,412 & $(35.1)$ & $776,210.5$ & 119.06 & $0.99[0.97,1.01]$ \\
\hline Advanced degree & 29,755 & 11,487 & (38.6) & $119,356.6$ & 96.24 & $0.62[0.60,0.65]$ \\
\hline Unknown & 13,906 & 2,041 & (14.7) & $20,521.7$ & 99.46 & \\
\hline \multicolumn{7}{|l|}{ Race } \\
\hline White & 804,727 & 270,589 & (33.6) & $2,345,963.5$ & 115.34 & ref \\
\hline Black & 206,230 & 83,469 & $(40.5)$ & $628,878.7$ & 132.73 & $1.03[1.01,1.05]$ \\
\hline Asian & 253,230 & 11,814 & $(4.7)$ & $98,426.4$ & 120.03 & $0.84[0.81,0.88]$ \\
\hline American Indian & 25,352 & 12,699 & $(50.1)$ & $124,820.3$ & 101.74 & $0.92[0.85,0.98]$ \\
\hline Other & 40,024 & 3,422 & $(8.5)$ & $29,924.3$ & 114.36 & $0.97[0.93,1.01]$ \\
\hline Unknown & 5,887 & 1,593 & $(27.1)$ & $16,808.5$ & 94.77 & \\
\hline \multicolumn{7}{|l|}{ Marital status } \\
\hline Single & 749,493 & 234,027 & $(31.2)$ & $2,095,914.4$ & 111.66 & ref \\
\hline Married & 314,816 & 136,895 & $(43.5)$ & $1,065,312.4$ & 128.50 & $1.16[1.14,1.18]$ \\
\hline Other $^{c}$ & 27,505 & 12,624 & $(45.9)$ & $82,962.2$ & 152.17 & $1.20[1.16,1.25]$ \\
\hline Unknown & 606 & 40 & (6.6) & 632.7 & 63.22 & \\
\hline
\end{tabular}

Note: Boldface indicates statistical significance $(p<0.05)$.

${ }^{\mathrm{a}}$ Cases $=$ individuals with a medical encounter for low back pain. The $\mathrm{n}$ for the total population and cases is provided, as well as the percentage (\%) of people in each category represented by the cases (row percentage).

${ }^{\mathrm{b}}$ Adjusted for sex, age, education, race, and marital status.

'Other includes divorced, widowed, or separated. 
Table 2. Adjusted Risk Ratios (RR) for Soldiers Developing Chronic or Recurrent Low Back Pain

\begin{tabular}{|c|c|c|c|c|c|c|}
\hline \multirow{2}{*}{$\begin{array}{l}\text { Demographics } \\
\text { Overall (\% of total) }\end{array}$} & \multicolumn{2}{|c|}{$\begin{array}{l}\text { Chronic/recurrent } \\
\text { cases } \mathrm{n}(\%)^{\mathrm{a}}\end{array}$} & \multicolumn{2}{|c|}{$\begin{array}{l}\text { Incident episode } \\
\text { only } \mathrm{n}(\%)^{\mathrm{a}}\end{array}$} & \multirow[t]{2}{*}{$\begin{array}{c}\text { Adjusted } \mathrm{RR}^{\mathrm{b}} \\
{[95 \% \mathrm{CI}]}\end{array}$} & \multirow[t]{2}{*}{$p$-value } \\
\hline & 104,169 & $(27.2)$ & 279,222 & $(72.8)$ & & \\
\hline \multicolumn{7}{|l|}{ Sex } \\
\hline Female & 23,246 & $(22.3)$ & 52,333 & $(18.7)$ & $1.20[1.18,1.21]$ & $<0.001$ \\
\hline Male & 80,923 & $(77.7)$ & 226,887 & $(81.3)$ & ref & \\
\hline Unknown & 0 & $(0.0)$ & 2 & $(<0.1)$ & & \\
\hline \multicolumn{7}{|l|}{ Age category } \\
\hline$<20$ & 27,784 & $(26.7)$ & 83,533 & $(29.9)$ & $0.93[0.91,0.94]$ & $<0.001$ \\
\hline $20-29$ & 51,546 & $(49.5)$ & 138,164 & $(49.5)$ & ref & \\
\hline $30-39$ & 19,808 & $(19.0)$ & 45,382 & $(16.3)$ & $1.11[1.09,1.12]$ & $<0.001$ \\
\hline$\geq 40$ & 4,958 & $(4.8)$ & 11,963 & $(4.3)$ & $1.09[1.06,1.12]$ & $<0.001$ \\
\hline Unknown & 73 & $(0.1)$ & 183 & $(0.1)$ & & \\
\hline \multicolumn{7}{|l|}{ Education category } \\
\hline $\begin{array}{l}\text { Did not finish high } \\
\text { school }\end{array}$ & 3,460 & $(3.3)$ & 8,789 & $(3.1)$ & $1.02[0.99,1.05]$ & 0.142 \\
\hline High school graduate & 71,727 & $(68.9)$ & 193,555 & $(69.3)$ & ref & \\
\hline College & 25,405 & $(24.4)$ & 66,945 & $(24.0)$ & $0.99[0.98,1.01]$ & 0.489 \\
\hline Advanced degree & 3,106 & $(3.0)$ & 8,366 & $(3.0)$ & $0.89[0.86,0.92]$ & $<0.001$ \\
\hline Unknown & 471 & $(0.5)$ & 1,567 & $(0.6)$ & & \\
\hline \multicolumn{7}{|l|}{ Race } \\
\hline White & 73,391 & $(70.5)$ & 197,025 & $(70.6)$ & ref & \\
\hline Black & 23,144 & $(22.2)$ & 60,310 & $(21.6)$ & $0.98[0.96,0.99]$ & $<0.001$ \\
\hline Asian & 3,271 & $(3.1)$ & 9,426 & $(3.4)$ & $0.93[0.90,0.96]$ & $<0.001$ \\
\hline American Indian & 923 & $(0.9)$ & 2,497 & $(0.9)$ & $0.97[0.92,1.03]$ & 0.338 \\
\hline Other & 3,019 & $(2.9)$ & 8,793 & $(3.1)$ & $0.89[0.86,0.92]$ & $<0.001$ \\
\hline Unknown & 421 & $(0.4)$ & 1,171 & $(0.4)$ & & \\
\hline \multicolumn{7}{|l|}{ Marital status } \\
\hline Single & 60,472 & $(58.1)$ & 173,470 & $(62.1)$ & ref & \\
\hline Married & 39,732 & $(38.1)$ & 97,063 & $(34.8)$ & $1.07[1.05,1.08]$ & $<0.001$ \\
\hline Other $^{\mathrm{c}}$ & 3,958 & $(3.8)$ & 8,656 & $(3.1)$ & $1.10[1.07,1.13]$ & $<0.001$ \\
\hline Unknown & 7 & $(<0.1)$ & 33 & $(<0.1)$ & & \\
\hline
\end{tabular}

Note: Boldface indicates statistical significance $(p<0.05)$.

${ }^{a}$ The percentage listed represents the column percentage for the respective variable.

${ }^{\mathrm{b}}$ Adjusted for sex, age, education, race, and marital status.

${ }^{\mathrm{c}}$ Other includes divorced, widowed, or separated. 
Table 3. Likelihood of Incident Low Back Pain (LBP) and Risk of Chronic or Recurrent LBP

\begin{tabular}{|c|c|c|c|c|c|c|}
\hline Comorbidity & $\begin{array}{l}\text { Cases of LBP } \\
(\mathrm{n}=383,586)\end{array}$ & Person-years & $\begin{array}{c}\text { Adjusted IRR }^{\mathrm{a}} \\
{[95 \% \mathrm{CI}]}\end{array}$ & $\begin{array}{c}\text { Chronic or } \\
\text { recurrent } \\
\text { cases } \\
(\mathrm{n}=104,169) \\
\end{array}$ & $\begin{array}{c}\text { Incident } \\
\text { episode only } \\
(\mathrm{n}=279,222)\end{array}$ & $\begin{array}{c}\text { Adjusted } \mathrm{RR}^{\mathrm{a}} \\
{[95 \% \mathrm{CI}]}\end{array}$ \\
\hline \multicolumn{7}{|c|}{ Psychological issues } \\
\hline Yes & 123,181 & $989,893.83$ & $1.01[1.00,1.03]$ & 41,492 & 81,625 & $1.39[1.38,1.41]$ \\
\hline No & 260,405 & $2,254,927.83$ & ref & 62,677 & 197,597 & ref \\
\hline \multicolumn{7}{|l|}{ Sleep disorders } \\
\hline Yes & 58,877 & $582,655.58$ & $0.80[0.78,0.81]$ & 22,653 & 36,189 & $1.52[1.50,1.53]$ \\
\hline No & 324,709 & $2,662,166.08$ & ref & 81,516 & 243,033 & ref \\
\hline \multicolumn{7}{|l|}{ Obesity } \\
\hline Yes & 53,909 & $514,600.00$ & $0.81[0.80,0.83]$ & 19,018 & 34,864 & $1.34[1.32,1.36]$ \\
\hline No & 329,677 & $2,730,221.67$ & ref & 85,151 & 244,358 & ref \\
\hline \multicolumn{7}{|l|}{ Tobacco use } \\
\hline Yes & 104,732 & $980,622.75$ & $0.88[0.86,0.89]$ & 35,088 & 69,565 & $1.37[1.36,1.39]$ \\
\hline No & 278,854 & $2,264,198.92$ & ref & 69,081 & 209,657 & ref \\
\hline \multicolumn{7}{|l|}{ Alcohol use } \\
\hline Yes & 32,249 & $333,979.50$ & $0.85[0.83,0.87]$ & 9,802 & 22,424 & $1.18[1.16,1.20]$ \\
\hline No & 351,337 & $2,910,842.17$ & ref & 94,367 & 256,798 & ref \\
\hline \multicolumn{7}{|c|}{ Number of comorbidities } \\
\hline 0 & 166,603 & $1,321,273.25$ & ref & 35,232 & 131,308 & ref \\
\hline 1 & 114,429 & $963,381.42$ & $0.91[0.89,0.92]$ & 31,667 & 82,691 & $1.31[1.29,1.32]$ \\
\hline 2 & 61,547 & $565,364.33$ & $0.82[0.80,0.84]$ & 20,810 & 40,702 & $1.60[1.57,1.62]$ \\
\hline 3 & 29,854 & $284,680.67$ & $0.79[0.77,0.81]$ & 11,658 & 18,178 & $1.85[1.82,1.88]$ \\
\hline 4 & 9,902 & $97,010.42$ & $0.79[0.75,0.82]$ & 4,218 & 5,677 & $2.05[2.00,2.10]$ \\
\hline 5 & 1,251 & $13,111.58$ & $0.74[0.66,0.83]$ & 584 & 666 & $2.24[2.11,2.38]$ \\
\hline
\end{tabular}

Note: Boldface indicates statistical significance $(p<0.05)$.

Adjusted Incidence Rate Ratios (IRR) are provided for soldiers developing LBP and Risk Ratios (RR) are provided for soldiers developing chronic or recurrent LBP for each comorbid condition. ${ }^{\mathrm{a}}$ Adjusted for sex, age, education, race, and marital status. 
Table 4. Characteristics of Surgery For All Low Back Pain Cases, 2002-2011

\begin{tabular}{|c|c|c|c|c|c|c|}
\hline \multirow{2}{*}{$\begin{array}{l}\text { Variable } \\
\text { Overall (\% of total) }\end{array}$} & \multicolumn{2}{|c|}{$\begin{array}{c}\text { Spinal surgery } \\
\mathrm{n}(\%)^{\mathrm{a}}\end{array}$} & \multicolumn{2}{|c|}{$\begin{array}{c}\text { No spinal surgery } \\
n(\%)^{\mathrm{a}}\end{array}$} & \multirow[t]{2}{*}{$\begin{array}{l}\text { Log binomial } \\
\text { regression } \\
\text { RR }[95 \% \mathrm{CI}]\end{array}$} & \multirow[t]{2}{*}{$\begin{array}{c}\text { AFT regression } \\
\text { TR }[95 \% \mathrm{CI}]\end{array}$} \\
\hline & 7,446 & (1.9) & 376,140 & $(98.1)$ & & \\
\hline \multicolumn{7}{|l|}{ Sex } \\
\hline Female & 767 & $(10.3)$ & 74,825 & (19.9) & $0.58[0.54,0.63]$ & $1.97[1.84,2.12]$ \\
\hline Male & 6,679 & (89.7) & 301,313 & $(90.1)$ & ref & ref \\
\hline \multicolumn{7}{|l|}{ Age } \\
\hline$<20$ & 480 & $(6.5)$ & 55,331 & $(14.7)$ & $0.63[0.57,0.69]$ & $1.51[1.38,1.66]$ \\
\hline $20-29$ & 3,756 & $(50.4)$ & 217,154 & $(57.7)$ & ref & ref \\
\hline $30-39$ & 2,383 & $(32.0)$ & 74,128 & (19.7) & $1.67[1.58,1.77]$ & $0.88[0.83,0.93]$ \\
\hline$>40$ & 819 & $(11.0)$ & 29,409 & $(7.8)$ & $1.53[1.41,1.67]$ & $0.87[0.80,0.95]$ \\
\hline \multicolumn{7}{|l|}{ Education } \\
\hline $\begin{array}{l}\text { Did not graduate high } \\
\text { school }\end{array}$ & 325 & (4.4) & 15,366 & $(4.1)$ & $0.95[0.85,1.06]$ & $0.82[0.73,0.91]$ \\
\hline High school graduate & 4,892 & $(65.7)$ & 255,486 & $(67.9)$ & ref & ref \\
\hline College & 1,878 & $(25.2)$ & 89,298 & $(23.7)$ & $0.95[0.90,1.00]$ & $0.96[0.91,1.01]$ \\
\hline Advanced degree & 331 & $(4.5)$ & 13,993 & $(3.7)$ & $0.77[0.68,0.86]$ & $1.14[1.01,1.28]$ \\
\hline \multicolumn{7}{|l|}{ Race } \\
\hline White & 6,057 & $(81.4)$ & 264,532 & $(70.3)$ & ref & ref \\
\hline Black & 916 & (12.3) & 82,553 & $(22.0)$ & $0.50[0.47,0.54]$ & $2.12[1.98,2.27]$ \\
\hline Other & 224 & $(3.0)$ & 11,590 & (3.1) & $0.66[0.58,0.76]$ & $2.00[1.76,2.27]$ \\
\hline Asian & 157 & (2.1) & 12,542 & (3.3) & $0.57[0.48,0.66]$ & $1.52[1.31,1.77]$ \\
\hline American Indian & 69 & $(0.9)$ & 3,353 & $(0.9)$ & $0.94[0.74,1.19]$ & $1.10[0.88,1.38]$ \\
\hline \multicolumn{7}{|l|}{ Marital status } \\
\hline Single & 2,375 & (31.9) & 180,961 & $(48.1)$ & ref & ref \\
\hline Married & 4,653 & $(62.5)$ & 179,154 & (47.6) & $1.42[1.34,1.5]$ & $0.85[0.80,0.90]$ \\
\hline Other ${ }^{\mathrm{b}}$ & 418 & (5.6) & 15,985 & (4.3) & $1.47[1.32,1.64]$ & $0.75[0.67,0.83]$ \\
\hline \multicolumn{7}{|l|}{ Comorbidities } \\
\hline Multiple & 2,422 & $(32.5)$ & 100,132 & $(26.6)$ & $1.27[1.2,1.34]$ & $0.49[0.46,0.52]$ \\
\hline Obesity & 316 & $(4.2)$ & 17,630 & $(4.7)$ & $0.99[0.88,1.11]$ & $0.88[0.79,0.98]$ \\
\hline Sleep disorders & 208 & (2.8) & 9,851 & (2.6) & $1.05[0.91,1.21]$ & $0.68[0.60,0.78]$ \\
\hline Tobacco use & 937 & (12.6) & 36,816 & $(9.8)$ & $1.33[1.24,1.44]$ & $0.58[0.54,0.63]$ \\
\hline Psychological issues & 619 & $(8.3)$ & 42,269 & $(11.2)$ & $0.90[0.82,0.98]$ & $0.90[0.83,0.98]$ \\
\hline Alcohol use & 85 & $(1.1)$ & 5,698 & $(1.5)$ & $0.92[0.75,1.15]$ & $0.85[0.70,1.05]$ \\
\hline None & 2,859 & $(38.4)$ & 163,744 & $(43.5)$ & ref & ref \\
\hline
\end{tabular}

Notes: Boldface indicates statistical significance $(p<0.05)$.

${ }^{a}$ The percentage listed represents the column percentage for the respective variable.

${ }^{\mathrm{b}}$ Other includes divorced, widowed, and separated

$\mathrm{RR}$, risk ratio; $\mathrm{AFT}$, accelerated failure time; TR, time ratio 